\title{
Central serous chorioretinopathy: a pathogenetic model
}

This article was published in the following Dove Press journal:

Clinical Ophthalmology

I8 Febuary 20I I

Number of times this article has been viewed

\author{
Antonio Caccavale ${ }^{1}$ \\ Filippo Romanazzi' \\ Manuela Imparato' \\ Angelo Negri ${ }^{2}$ \\ Anna Morano ${ }^{3}$ \\ Fabio Ferentini ${ }^{2}$ \\ 'Department of Ophthalmology, \\ Neuropthalmology and Ocular \\ Immunology Service, ${ }^{2}$ Department of \\ Ophthalmology, Hospital "C. Cantù", \\ Abbiategrasso, Milan, Italy; ${ }^{3}$ University \\ Eye Clinic, Foundation IRCCS San \\ Matteo Hospital, Pavia, Italy
}

Correspondence: Antonio Caccavale Hospital "C. Cantù" Abbiategrasso, 2008I Milan, Italy

Tel +39029486202

Fax +39029486202

Email neureye@katamail.com
Abstract: Despite numerous studies describing predominantly its demography and clinical course, many aspects of central serous chorioretinopathy (CSCR) remain unclear. Perhaps the major impediment to finding an effective therapy is the difficulty of performing studies with large enough cohorts, which has meant that clinicians have focused more on therapy than on a deeper understanding of the pathogenesis of the disease. Hypotheses on the pathogenesis of CSCR have ranged from a basic alteration in the choroid to an involvement of the retinal pigment epithelium (RPE). Starting from evidence that affected subjects often present a personality prone to stress with altered pituitary-hypothalamic axis response (HPA) and that they have higher levels of serum and urinary cortisol and catecholamines than healthy subjects, we hypothesize a cascade of events that may lead to CSCR through hypercoagulability and augmented platelet aggregation. In particular we investigated the role of tissue plasminogen activator, increasing plasminogen activator inhibitor 1 (PAI-1), and plasmin- $\alpha 2$ - plasmin inhibitor complexes. We reviewed the different therapeutic approaches, including adrenergic antagonists, carbonic anhydrase inhibitors, mifepristone, ketoconazole, laser photocoagulation, intravitreal injection of bevacizumab, and photodynamic therapy with verteporfin (PDT) and our model of pathogenesis seems to be in agreement with the clinical effects obtained from these treatments. In accord with our thesis, we began to treat a group of patients affected by CSCR with low-dose aspirin (75-100 mg), because of its effectiveness in other vascular diseases and its low ocular and general toxicity with prolonged use. The formulation of a causative model of CSCR enables us to understand how the therapeutic approach cannot be based on a generalized therapy but should be individualized for each patient, and that sometimes a combined strategy of treatment is required. Moreover a complete knowledge of the disease will help to identify patients prone to the most persistent forms of CSCR, and thus help to find a treatment.

Keywords: CSCR, aspirin, PAI-1, glucocorticoid, macula, pathogenesis

\section{Introduction}

Central serous chorioretinopathy (CSCR) has been described by various names for nearly a century and a half. ${ }^{1-3}$ Despite numerous studies on this disease over the years, many aspects of CSCR remain unclear. Extensive literature describes predominantly its demography and the clinical course. ${ }^{4}$ The research has been limited by lack of homogeneity in the stage of CSCR in the cohort studies.

In general most authors have turned their attention to finding an effective strategy of treatment rather than trying to identify causes of, and contributing factors to, the occurrence of the CSCR.

Although CSCR has been described as a benign and self-limiting disease, it has a tendency to re-occur, with decreased visual function. ${ }^{5-7}$ 
The need for early treatment emerges from clinical evidence which stresses that if the resolution of the neuroepithelial detachment occurs within 4 months after onset of symptoms it is possible to reduce the incidence of retinal atrophy and the consequent decrease in visual acuity. ${ }^{8}$

\section{Pathogenesis}

Hypotheses on the pathogenesis of CSCR range from a basic alteration in the choroid to an involvement of the retinal pigment epithelium (RPE).

As such, the treatment of CSCR has had either the RPE or choroid as the primary target, and sometimes effectiveness of therapy has been difficult to demonstrate. The advent of fluorescent angiography and indocyanine green angiography (ICGA) helped to improve understanding of the anatomical structure primarily involved in determining the development of the disease. ${ }^{9-13}$

A crucial breakthrough in understanding CSCR came from a report, that affected subjects often present a stressful personality with altered pituitary-hypothalamic axis (HPA) response. ${ }^{14}$

Furthermore, patients affected by CSCR often have higher levels of serum and urinary cortisol and catecholamines than healthy subjects. ${ }^{15-17}$ Subsequently it was reported that therapies with local or systemic steroids can cause the disease, and glucocorticoids were identified as the main risk factor for the onset of CSCR ${ }^{18-20}$ Another consideration is that CSCR has also been described as a complication of diseases that have as their common denominator a condition of hypercoagulability and augmented platelet aggregation. These alterations can induce microthrombus formation and increase blood viscosity. ${ }^{21}$ It may be that these alterations are capable of affecting choroidal microcirculation.

Studies of eyes with CSCR using ICGA show abnormal choroidal perfusion and congestion of venous outflow. ${ }^{22,23}$

Circulatory disorders and areas of lobular hypoperfusion are frequently described in addition to an increased choroidal permeability. These results, seemingly at odds, are the consequence of the same hemorheologic disorder underpinning the onset of the CSCR. Effects of glucocorticoids on vascular reactivity ${ }^{24}$ have been described in patients affected by Cushing's syndrome.

In this disease there is an augmented vascular response, due to the glucocorticoid excess, to noradrenaline and angiotensin II with consequent hypertensive response. ${ }^{25}$ Administration of exogenous glucocorticoids in healthy volunteers was able to reproduce the same effect. ${ }^{26}$
The application of glucocorticoids to conjunctiva or skin is able to determine a vasoconstrictive response ${ }^{27}$ that can be inhibited by the local or systemic administration of glucocorticoid antagonists. ${ }^{28}$

In addition, glucocorticoids increase platelet aggregation and, by causing a reduction in the tissue plasminogen activator and increasing plasminogen activator inhibitor 1 (PAI-1) and the plasmin- $\alpha 2-$ plasmin inhibitor complexes, create the condition for increased microthrombus formation and increased blood viscosity. ${ }^{29}$ Also patients with chronic psychological distress, with an increased reactivity of HPA, frequently show a condition of systemic hypertension induced by an increase in vascular resistance. ${ }^{30}$

Vascular bed reduction due to vasoconstriction and to capillary occlusion, combined with higher resistance and increased blood viscosity, determine a sectorial hypoperfusion and an increase in the endoluminal pressure perfusion in the surrounding healthy vascular bed.

The increased endoluminal pressure determines the leakage of serum and small molecules in the stroma causing a further vascular tamponade. Since choroidal blood flow can be described by Hagen-Poiseuille's law $\left(\Delta \mathrm{P}=8 \mu \mathrm{LQ} / \pi \mathrm{r}^{4}\right)$, it follows that small differences in total radius of vascular bed induce a high increase in endovascular pressure with fluid extravasation and, in the same direction, a variation in viscosity $(\mu)$ determines a modification of choriocapillaris hemodynamics. ${ }^{31-33}$

The affinity of the disease for the macular area is due to the particular organization of the choriocapillaris with a closer meshwork than the peripheral choroid. ${ }^{34}$

This cascade of events led by corticoids seems to be in agreement with documented observations of fluorescent angiography and ICGA obtained in CSCR patients.

Articles that highlight the occlusion or hypoperfusion of choricapillaris do not conflict with those that show an increase in capillary permeability but likely represent the same hemorheological alteration at different times. The anatomical impact of these hemoreologic variations comprises the decompensation and detachment of the RPE and the subsequent neuroepithelial detachment. At this stage the clinical appearance will be that of typical CSCR. This cascade of events is summarized in Figure 1.

\section{Treatment}

Evidence emerging from the studies of different therapeutic approaches seems to be in agreement with our proposed model of pathogenesis. 


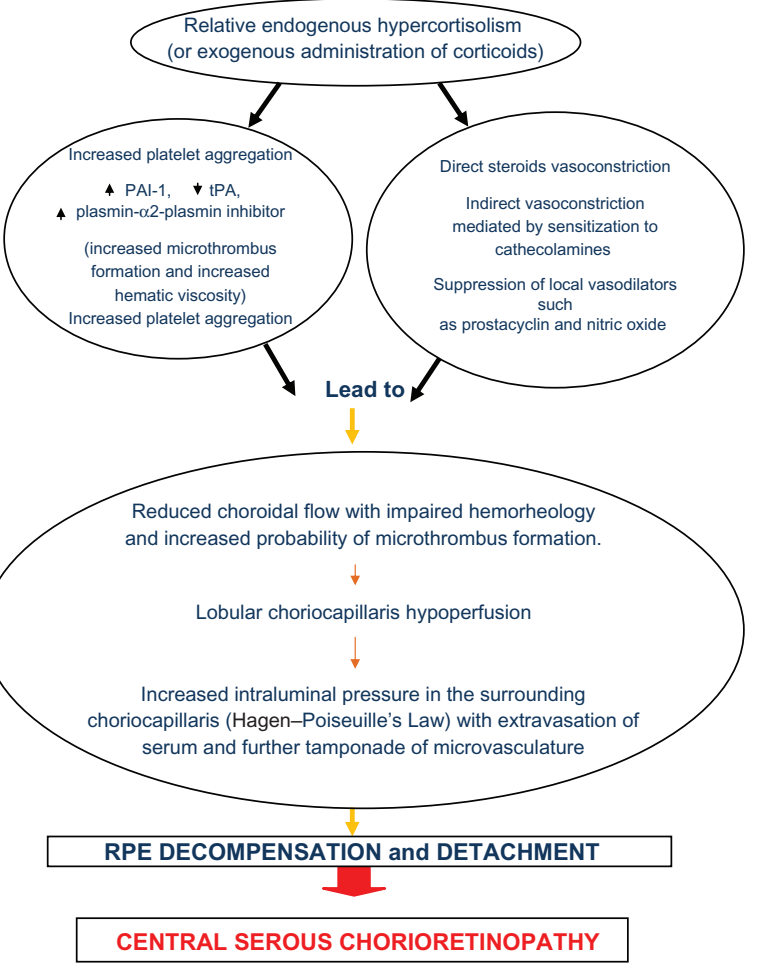

(In cases of prolonged course of disease or when risk factors persist, CSCR can become chronic or multifocal)

Figure I Central serous chorioretinopathy: a pathogenetic model. Abbreviations: CSCR, central serous chorioretinopathy; PAI-I, plasminogen activator inhibitor I; RPE, retinal pigment epithelium; tPA, tissue plasminogen activator.

The use of adrenergic antagonists was one of the first attempts to treat CSCR. Adrenergic antagonists reduce the effect of vasoconstriction by blocking adrenergic receptor activation induced by glucorticoids. ${ }^{35}$ In order to reduce the adrenergic tone, thought to be behind the vasospastic condition, even ablation of the stellate ganglion was used. ${ }^{36}$

Later treatment with $\alpha$-adrenergic antagonists was tried, ${ }^{37}$ then abandoned because of systemic side effects, and currently $\beta$-adrenergic antagonists are used because they have fewer side effects. ${ }^{38-41}$

Another attempt was made with the carbonic anhydrase inhibitors that act on RPE, contributing in part to the resorption of the subretinal fluid..$^{42}$ Recent studies show that both systemic acetazolamide and dorzolamide for topical use can increase choroidal blood flow. ${ }^{43-45}$ In the specific case of CSCR, in which a deficiency of choroidal blood flow has been described, carbonic anhydrase inhibitors could be effective.

The difficulty in predicting which patients will face a chronic and relapsing disease, resulting in impaired visual function, has led to a search for drugs that can be effective in the treatment of CSCR by reducing the activity or the serum level of endogenous glucocorticoids. This pharmacological approach is interesting because it is directed against one of the better known factors in the genesis of the CSCR.

Mifepristone is an antagonist of glucocorticoids and progesterone receptors with a weak antiandrogen action and has a good safety and tolerability profile. In addition, mifepristone inhibits cortisol-induced peripheral vasoconstriction. Ketoconazole exerts its effects by inhibiting some steps in the steroid synthesis resulting in decreased levels of cortisol, androgen, and aldosterone and in elevated progesterone. These effects seem to be present at the minimum dosage of $400 \mathrm{mg} /$ day. An additional action of ketoconazole is the direct antiglucocorticoid effect as an antagonist at the receptor level. Current studies on these two medications are, however, limited by the short follow-up and the number of patients recruited. ${ }^{46-48}$ Moreover, use of both mifepristone and the ketaconazole may be limited by important side effects.

As noted previously, the advent of ICGA in the study of the characteristics of choroidal circulation in patients with CSCR, and the accumulation of clinical cases of CSCR linked to systemic diseases, suggested that a disorder of choroidal blood flow could be critical in the development of the disease.

The increase in procoagulant blood factors, in particular PAI-1, was found in patients with CSCR. ${ }^{21,49}$

Moreover an increase in platelet aggregation can be induced by glucocorticoids and these factors suggested to us that a treatment that improves choriocapillaris hemodynamics and reduces PAI-1 could prevent the development of CSCR. We identified low-dose aspirin as a drug better suited for this purpose, because of its effectiveness in other vascular diseases and its low ocular and general toxicity with prolonged use. ${ }^{50,51}$ Besides its hemodynamic effects, aspirin reduces the stress response of the HPA axis, limiting the increase in serum cortisol and catecholamines. ${ }^{52,53}$ The putative mechanism of action of aspirin in the treatment of CSCR is therefore 2-fold: first, a purely hemoreologic action and, second, controlling the hyperfunction of the HPA axis. However aspirin, at greater doses, could have a paradoxical effect of vasoconstriction and predisposing to local and systemic hemorrhagic events. A dosage of 75 to $100 \mathrm{mg}$ appears to be best, with a profile of effectiveness/side-effects as evidenced by extensive cardiologic trials. ${ }^{54,55}$

The pathogenetic model we have described appears to be in agreement with the effectiveness of laser photocoagulation and photodynamic therapy with verteporfin in selected cases of CSCR. 
The mechanism of action of laser photocoagulation in CSCR still seems unclear, given that a full-thickness photocoagulation is not needed to assess the effectiveness of treatment.

Recent theories speculate that the effectiveness of the treatment is due to activation of cytokines secreted from the RPE which reduces vascular permeability and rearranges the microvascular choroidal network. ${ }^{56}$

The effectiveness of verteporfin for CSCR, especially in chronic forms and with large areas of RPE decompensation, seems to be attributable to a reduction in the permeability of the hyperfluorescent areas seen by ICGA and to a subsequent remodeling of the vascular bed which could rebalance perfusion pressure gradients previously altered. ${ }^{57}$

Intravitreal injection of bevacizumab is another recent approach to the treatment of CSCR. ${ }^{58}$ Growing literature highlights how this type of treatment has a degree of effectiveness in reducing neuroepitelial detachment and choroidal hyperpermeability. The mechanism of action seems to be linked to a reduction in vascular permeability. However in CSCR an increase of vascular endothelial growth factor (VEGF) was not found in the aqueous humor. ${ }^{59}$ It is possible that bevacizumab acts on constitutional choroidal VEGF. The anti-VEGF treatment also increases occludin between RPE cells, increasing the external retinal barrier. ${ }^{60}$

\section{Conclusion}

The formulation of a causative model of CSCR allows us to understand how the therapeutic approach cannot be based on a generalized therapy but should be individualized for each patient, and that sometimes a combined strategy of treatment is required, which acts on the various steps that may determine the expression and maintenance of the disease.

To avoid the establishment of chronic disease, early intensive treatment is necessary to reduce the episodes of relapse.

In future a better discrimination of the precise molecular mechanisms involved in the susceptibility of individuals to glucocorticoids, and a more complete knowledge of the risk factors, could help to identify patients prone to the most persistent forms of CSCR.

\section{Acknowledgments}

We wish to thank Dr Ralph Levinson and Dr Luciano Prosperi for their their support and collaboration to our work.

\section{Disclosure}

Authors report no conflicts of interest in this work.

\section{References}

1. Von Graefe A. Ueber centrale recidivirende Retinitis. Albrecht von Graefe's Arch Klin Ophthalmol. 1866;12:211.

2. Horniker E. Ueber eine Form von zentraler Retinitis auf angioneurotischer Grundlage [Retinitis centralis angioneurotica]. Albrecht von Graefe's Arch Klin Ophthalmol. 1930;123:286.

3. Gass JDM. Pathogenesis of disciform detachment of the neuroepithelium. Am J Ophthalmol. 1967;63:587.

4. Wang M, Munch CI, Hasler PW, Prunte C, Larsen M. Central serous chorioretinopathy. Acta Ophthalmol. 2008;86:126-145.

5. Klein ML, van Buskirk ME, Friedman E, Gragoudas E, Chandra S. Experience with nontreatment of central serous choroidopathy. Arch Ophthalmol. 1974;91:247-250.

6. Yap EY, Robertson DM. The long-term outcome of central serous chorioretinopathy. Arch Ophthalmol. 1996;114:689-692.

7. Bujarborua D. Long-term follow-up of idiopathic central serous chorioretinopathy without laser. Acta Ophthalmol Scand. 2001;79: 417-421.

8. Wang MS, Sander B, Larsen M. Retinal atrophy in idiopathic central serous chorioretinopathy. Am J Ophthalmol. 2002;133:787-793.

9. Hayashi $\mathrm{K}$, Hasegawa $\mathrm{Y}$, Tokoro T. Indocyanine green angiography of central serous chorioretinopathy. Int Ophthalmol. 1986;9: $37-41$.

10. Piccolino FC, Borgia L. Central serous chorioretinopathy and indocyanine green angiography. Retina. 1994;14:231-242.

11. Iida T, Hagimura N, Otani T, Ikeda F, Muraoka K. Choroidal vascular lesions in serous retinal detachment viewed with indocyanine green angiography. Nippon Ganka Gakkai Zasshi. 1996;100:817-824.

12. Giovannini A, Scassellati-Sforzolini B, D'Altobrando E, Mariotti C, Rutili T, Tittarelli R. Choroidal findings in the course of idiopathic serous pigment detachment detected by indocyanine green videoangiography. Retina. 1997:17:286-293.

13. Menchini U, Virgili G, Lanzetta P, Ferrari E. Indocyanine green angiography in central serous chorioretinopathy. Int Ophthalmol. 1997; 21:57-69.

14. Yannuzzi LA. Type a behavior and central serous chorioretinopathy. Retina. 1987;7:111-131.

15. Bouzas EA, Scott MH, Mastorakos G, Chrousos GP, Kaiser-Kupfer MI. Central serous chorioretinopathy in endogenous chorioretinopathy. Arch Ophthalmol. 1993;111:1229-1233.

16. Haimovici R, Rumelt S, Melby J. Endocrine abnormalities in patients with central serous chorioretinopathy. Ophthalmology. 2003; 110:698-703.

17. Tewari HK, Gadia R, Kumar D, Venkatesh P, Garg SP. Sympatheticparasympathetic activity and reactivity in central serous chorioretinopathy: a case-control study. Invest Ophth Vis Sci. 2006;47: 3474-3478.

18. Song E, Wakakura M, Ishikawa S. Central serous chorioretinopathy induced by corticosteroids. Nippon Ganka Gakkai Zasshi. 1997; 101:257-264.

19. Bouzas EA, Karadimas P, Pournaras CJ. Central serous chorioretinopathy and glucocorticoids. Surv Ophthalmol. 2002;47:431-448.

20. Haimovici R, Koh S, Gagnon DR, Lehrfeld T, Wellik S. Risk factors for central serous chorioretinopathy: a case control study. Ophthalmology. 2004;111:244-249.

21. Yamada R, Yamada S, Ishii A, Tane S. Evaluation of tissue plasminogen activator and plasminogen activator inhibitor-1 in blood obtained from patients of idiopathic central serous chorioretinopathy. Nippon Ganka Gakkai Zasshi. 1993;97:955-960.

22. Iida T, Kishi S, Hagimura N, Shimizu K. Persistent and bilateral choroidal vascular abnormalities in central serous chorioretinopathy. Retina. 1999; 19:508-512.

23. Kitaya N, Nagaoka T, Hikichi T. Features of abnormal choroidal circulation in central serous chorioretinopathy. Br J Ophthalmol. 2003; 87:709-712.

24. Yang S, Zhang L. Glucocorticoids and vascular reactivity. Curr Vasc Pharmacol. 2004;2:1-12. 
25. Saruta T, Suzuki H, Handa M, Igarashi Y, Kondo K, Senba S. Multiple factors contribute to the pathogenesis of hypertension in Cushing's syndrome. J Clin Endocrinol Metab. 1986;62:275-279.

26. Whitworth JA, Connell JM, Lever AF, Fraser R. Pressor responsiveness in steroid-induced hypertension in man. Clin Exp Pharmacol Physiol. 1986;13:353-358.

27. Walker BR, Williams BC. Corticosteroids and vascular tone: mapping the messenger maze. Clin Sci. 1992;82:597-605.

28. Gaillard RC, Poffet D, Riondel AM, Saurat JH. RU 486 inhibits peripheral effects of glucocorticoids in humans. J Clin Endocrinol Metab. 1985;61:1009-1011.

29. Jones JP Jr. Intravascular coagulation and osteonecrosis. Clin Orthop. 1992;277:41-53.

30. Nyklícek I, Bosch JA, Amerongen AV. A generalized physiological hyperreactivity to acute stressors in hypertensives. Biol Psychol. 2005;70:44-51.

31. Williamson TH, Harris A. Ocular blood flow measurement. Br J Ophthalmol. 1994;78:939-945.

32. Flower RW, Fryczkowski AW, Scott McLeod D. Variability in choriocapillaris blood flow distribution. Inv Ophthalmol Vis Sci. 1995; 36:1247-1258.

33. Flower RW, von Kerczek C, Zhu L, Ernest A, Eggleton C, Topoleski LDT. Theoretical investigation of the role of choriocapillaris blood flow in the treatment of subfoveal choroidal neovascularization associated with age-related macular degeneration. Am J Ophthalmol. 2001;132:85-93.

34. Hayreh SS. Segmental nature of the choroidal vasculature. Br J Ophthalmol. 1975;59:631-48.

35. Haigh RM, Jones CT. Effect of glucocorticoids on alpha 1-adrenergic receptor receptor binding in rat vascular smooth muscle. $J \mathrm{Mol}$ Endocrinol. 1990;5:42-48.

36. Matsuura M, Ando F, Matsuura M. Stellate ganglion block therapy in central serous chorioretinopathy. Nippon Ganka Gakkai Zasshi. 1981;85:1485-1491.

37. Heinrich MR. Central serous retinopathy and alpha-blockaders. Bull Soc Ophtalmol Fr. 1994;74:681-683.

38. Fabianová J, Porubská M, Cepilová Z. Central serous chorioretinopathytreatment with beta blockers. Cesk Slov Oftalmol. 1998;54:401-404.

39. Avci R, Deutman AF. Treatment of central serous choroidopathy with the beta receptor blocker metoprolol. Klin Monbl Augenheilkd. 1993;202:199-205.

40. Chrapek O, Spacková K, Rehák J. Treatment of central serous chorioretinopathy with beta blockers. Cesk Slov Oftalmol. 2002;58:382-386.

41. Browning DJ. Nadolol in the treatment of central serous chorioretinopathy. Am J Ophthalmol. 1993;116:770-771.

42. Pikkel J, Beiran I, Ophir A, Miller B. Acetazolamide for central serous retinopathy. Ophthalmology. 2002;109:1723-1725.

43. Dallinger S, Bobr B, Findl O, Eichler HG, Schmetterer L. Effects of acetazolamide on choroidal blood flow. Stroke. 1998;29:997-1001.

44. Kiss B, Dallinger S, Findl O, Rainer G, Eichler HG, Schmetterer L. Acetazolamide-induced cerebral and ocular vasodilation in humans is independent of nitric oxide. Am J Physiol. 1999;276:R1661-R1667.
45. Fuchsjäger-Mayrl G, Wally B, Rainer G, et al. Effect of dorzolamide and timolol on ocular blood flow in patients with primary open angle glaucoma and ocular hypertension. Br J Ophthalmol. 2005;89: 1293-1297.

46. Nielsen JS, Weinreg RN, YannuzziL, Jampol LM. Mifepristone treatment of chronic central serous chorioretinopathy. Retina. 2007; 27:119-122.

47. Meyerle CB, Freund KB, Bhatnagar P, Shah V, Yannuzzi LA. Ketoconazole in the treatment of chronic idiopathic central serous chorioretinopathy. Retina. 2007;27:943-946.

48. Golshahi A, Klingmüller D, Holz FG, Eter N. Ketoconazole in the treatment of central serous chorioretinopathy: a pilot study. Acta Ophthalmol. 2010;88:576-581.

49. Iijima H, Iida T, Murayama K, Imai M, Gohdo T. Plasminogen activator inhibitor 1 in central serous chorioretinopathy. Am J Ophthalmol. 1999; $127: 477-478$.

50. Caccavale A, Imparato M, Romanazzi F, Negri A, Porta A, Ferentini F. A new strategy of treatment with low-dosage acetyl salicylic acid in patients affected by central serous chorioretinopathy. Med Hypotheses. 2009;73:435-437.

51. Caccavale A, Romanazzi F, Imparato M, Negri A, Morano A, Ferentini F. Low-dose aspirin as treatment for central serous chorioretinopathy. Clin Ophthalmol. 2001;4:899-903.

52. Nye EJ, Hockings GI, Grice JE, et al. Aspirin inhibits vasopressininduced hypothalamic-pituitary-adrenal activity in normal humans. J Clin Endocrinol Metab. 1997;82:812-817.

53. Di Luigi L, Guidetti L, Romanelli F, Baldari C, Conte D. Acetylsalicylic acid inhibits the pituitary response to exercise-related stress in humans. Med Sci Sports Exerc. 2001;33:2029-2035.

54. Roth GJ, Calverley DC. Aspirin, platelets and thrombosis: theory and practice. Blood. 1994;83:885-898.

55. Collaborative overview of randomized antiplatelet therapy-1: Prevention of death, myocardial infarction, and stroke by prolonged antiplatelet therapy in various categories of patients. Antiplatelet Trialists' Collaboration. BMJ. 1994;308:81-106.

56. Sivaprasad S, Elagouz m, McHugh D, Shona O, Dorin G. Micropulsed diode laser therapy: evolution and clinical application. Surv Ophthalmol. 2010;55:516-530.

57. Inoue R, Sawa M, Tsujikawa M, Gomi F. Association between the efficacy of photodynamic therapy and indocyanine green angiography findings for central serous chorioretinopathy. Am J Ophthalmol. 2010;149:441-446.

58. Niegel MF, Schrage NF, Christmann S, Degenring RF. Intravitreal bevacizumab for chronic central serous chorioretinopathy. Ophthalmologe. 2008;105:943-945.

59. Lim JW, Kim MU, Shin MC. Aqueous humor and plasma levels of vascular endothelial growth factor and interleukin-8 in patients with central serous chorioretinopathy. Retina. 2010;30:1465-1471.

60. Wolfensberger TJ, Gregor ZJ. Macular edema - rationale for therapy. Dev Ophthalmol. 2010;47:49-58.
Clinical Ophthalmology

\section{Publish your work in this journal}

Clinical Ophthalmology is an international, peer-reviewed journal covering all subspecialties within ophthalmology. Key topics include: Optometry; Visual science; Pharmacology and drug therapy in eye diseases; Basic Sciences; Primary and Secondary eye care; Patient Safety and Quality of Care Improvements. This journal is indexed on Submit your manuscript here: http://www.dovepress.com/clinical-ophthalmology-journa

\section{Dovepress}

PubMed Central and CAS, and is the official journal of The Society of Clinical Ophthalmology (SCO). The manuscript management system is completely online and includes a very quick and fair peer-review system, which is all easy to use. Visit http://www.dovepress.com/ testimonials.php to read real quotes from published authors. 